2016 Modular and Offsite Construction (MOC) Summit

Edmonton, Alberta, Canada, September 29 - October 01, 2016

\title{
3D/4D VISUALIZATION FRAMEWORK FOR MODELLING OFF-SITE PRODUCTIVITY OF MODULAR CONSTRUCTION HOUSING
}

\author{
Jad JUREIDINI $^{1 *}$, Mona AFIFI ${ }^{2}$, Rita ZHANG $^{3}$, and Dr. Mohamed AL-HUSSEIN ${ }^{4}$ \\ ${ }^{1}$ MSc Candidate, Department of Civil \& Environmental Engineering, University of Alberta \\ ${ }^{2}$ Post-doctoral Fellow, Department of Occupational Therapy, University of Alberta \\ ${ }^{3}$ PhD Candidate, Department of Civil \& Environmental Engineering, University of Alberta \\ ${ }^{4}$ Professor, Department of Civil \& Environmental Engineering, University of Alberta \\ *Corresponding author's e-mail:jureidin@ualberta.ca
}

\begin{abstract}
Construction, as the process of constructing a building, has diverse range of available software tools which have been developed to support modelling operations, tasks, and processes in the construction industry. 3D visualization as a modelling tool has been widely used to improve modular and off-site construction activities; it allows for seamless information sharing and collaboration among project stakeholders, and also provides opportunities for improvements suggested by the project team. This paper presents a framework for modelling the off-site modular construction of housing at the Kent Homes manufacturing facility through 3D/4D visualization. A case study is represented to illustrate the potential for production improvement.
\end{abstract}

\section{KEYWORDS}

Modular, construction, visualization, 3D

\section{INTRODUCTION}

Visualization has been proposed as a tool to deal more effectively with the complexity, scale, and diversity associated with construction projects. Arthur Brisbane (1911) conjured the phrase, "Use a picture. It's worth a thousand words." This characterizes one of the goals and benefits of visualization: that anything complex or difficult to understand may be more easily comprehended if represented in a visual medium. In the late $19^{\text {th }}$ century, Gustave Flaubert coined the term, "God is in the details", that is, it is necessary to leave nothing out of consideration and that what is being done must be done thoroughly. Hence, using pictures loaded with detailed building information enhance the $3 \mathrm{D} / 4 \mathrm{D}$ visualization. In this sense, the use of $3 \mathrm{D} / 4 \mathrm{D}$ visualization has another benefit: that the realism of the visualization being produced may identify certain subtleties that are not necessarily quantified, may be condoned, but, nonetheless possess some significance in the overall construction operation. 
Objects and operations can be modelled as 2D still images and/or 3D virtual objects and/or over the 4 th dimension of time to measure progress. 3D/4D modelling is useful for two specific reasons: first, experienced workers mentally evaluate and visualize the means by which they will carry out their operations; second, at some point these experienced workers must convey their thought process and plan to other members of the project team. Thus, visualization would assist these workers with their evaluations and also with communicating effectively. The benefits of visualization are two-fold. It allows a person to better comprehend and process information as well as communicate this information to others (Burkhard, 2004). It has been recognized as a tool to overcome barriers that segregate professionals and parties involved with construction projects. Using a healthcare project as a case study, Khanzode et al. (2008) identified the shortcomings associated with using 2D visuals to communicate information between MEP contractors. Such limitations include: inabilities to identify conflicts because of 2D representations; delays in construction caused by uncovered conflicts; rework caused by unidentified issues during the design phase; increased site supervision to prevent conflict between contractors; and increased administrative burden associated with change orders because of conflicts discovered after budget approvals.

Visualization, as a means of communication, can overcome fragmentation between professionals in the construction industry. The reason for this is that a variety of visual graphics and images can more effectively convey and communicate specific information than the traditional text and/or charts. This paper proposes a framework based on 3D/4D visualization of the off-site modular construction of housing at the Kent Homes facility in Bouctouche, New Brunswick. The paper begins with a brief outline of the theoretical background and previous research on visualization as a modelling tool that is being used to improve various aspects of construction activities. The framework is represented through an integrated approach that incorporates project stockholders' expertise and the proposed 3D/4D visualization. A case study of a prototype modular housing at Kent Homes is illustrated to outline the effectiveness of $3 \mathrm{D} / 4 \mathrm{D}$ visualization in detecting any malfunctions throughout the construction production line and investigating applicable potential improvements.

\section{D/4D VISUALIZATION APPLICATION IN CONSTRUCTION}

Modelling of the construction processes continues to undergo refinement; however, this takes places in 2D, thus depicting the models in 3D/4D is not only useful but also necessary. Construction systems and operations cannot be depicted in 2D space alone, for there are too many degrees of freedom within which to carry out construction operations. More importantly, analysts of simulation outputs may have reservations with the text and chart results they are viewing; their main concern would be the lack of graphical support tools that can depict the modeled operations; otherwise known as the "black box" effect (Kamat \& Martinez, 2000). This explains why specific software that allows for the 3D/4D modelling of construction objects and operations has become so important; it also supplements the prominent development of simulation software with regard to construction. The resulting correlation is between the simulation of construction operations, the visualization of these simulations and their results, and the refined management of construction tasks as a result of the model and its visualization.

The prominence of 3D/4D modelling comes from the simple premise that visualizing is easier with a designated tool rather than visualizing in one's own mind. In one's own mind, a person must 
associate project information with their own graphical depictions of the project involved. But with a given tool, such as a software program, the project information is retained while the project is graphically displayed. Some construction managers are able to visualize information and processes in their heads, but this is a skill that is developed through years of experience. Furthermore, communicating their knowledge to others can prove to be a challenge. The benefit of $3 \mathrm{D} / 4 \mathrm{D}$ visualization is that the person viewing the information is able to focus more efficiently on fewer tasks. In certain experiments, it was directly demonstrated that visualizing construction planning in the $4^{\text {th }}$ dimension made that schedule easier to comprehend than simply reading it in a traditional format (Kang \& Lho, 2003; Messner \& Horman, September, 2003). Thus, the 3D/4D visualization with certain construction information can improve understanding because visual images require less effort than text for the mind to comprehend. These benefits include less rework; increased productivity; fewer requests for information; fewer change orders; less increase in cost; and, a decrease in time from start of construction to facility turnover (Staub-French \& Khanzode, 2007). Currently, the areas of application of 3D/4D modelling include: photorealistic renderings for presentation and marketing purposes; design reviews for meetings to communicate and collaborate on project issues; analyses on design options and building operations, to facilitate a better understand for all parties involved the options available to reach construction project completion; analyses on construction operations, which link construction schedules with 3D models (Hartmann, Gao, \& Fischer, 2008).

One issue associated with visualization is interoperability. There is undergoing research that is directly responding to this. In this issue, specific tools used for visualizing information are not always compatible or even interoperable with other tools, visual-based or otherwise. It can be difficult to exchange information between two or more software programs. What is consequently required is time to manually input all the necessary information per program (Bazjanac, 2002). Another issue is the use of visual-based software tools. The benefits realized from applying visualization have been acknowledged in some case studies, but the applications have only been made periodically and to a specific and small number of areas of the project lifecycle. Proponents of visualization in the construction industry would argue that its application can extend to the rest of the project lifecycle. One possible explanation for this is that there is no established framework or set of guidelines on the application of visualization throughout project lifecycles. Without such a framework, it is up to the practitioners to realize this themselves. This may explain why visualization has been applied to the design phase more extensively than the construction phase, and to the construction phase more than the operation phase.

\section{VISUALIZATION APPROACH FOR COMMUNICATION AND PRODUCTION IMPROVEMENT}

$3 \mathrm{D} / 4 \mathrm{D}$ visualization has been used as a tool for manufacturing construction improvement through investigating hidden problems and facilitating communication between various project parties. Additionally, 3D/4D visualization has been proposed to validate future suggested improvements. The 3D/4D visualization report is a useful tool that allows the plant manager to see the hidden issues and facilitate changes in the plant based on these issues. However, not only does it take time for management level personnel to realize the issues, but it also requires effort to persuade employees or on-site workers to implement changes to their current practice based on suggestions from someone who spends very little time in the factory. Workers also have difficulty seeing how 
their own process affects the whole production line or accepting the critiques from an outsider; instead they will tend to ask for prerequisite changes priory to their tasks. The objective of creating a proper $3 \mathrm{D} / 4 \mathrm{D}$ visualization report is to be able to mimic the actual production line procedure in order to remarkably reducing the potential of non-effective human to human communication, a measured type of waste from the lean manufacturing perspective.

The 3D/4D visualization framework must be created based on an applicable plant procedure. Based on an implementation experience with an industry partner company, the following four factors that are critical to create an effective 3D/4D visualization were concluded:

(1) Identify real case scenario that mimics the best practice possible.

(2) Provide procedures with the highest level of relevant detail based on the objective of the visualization required by the company. Any details that do not bring any value related to the visualization objectives should be eliminated.

(3) Set up the visualization with proper speed or providing extra details in order to help to reveal and emphasize the problems.

The second potential for $3 \mathrm{D} / 4 \mathrm{D}$ visualization is to help validate the future stage prior to implementation. A plant manager seeking for production line improvement, aside from the effort to assess the return on investment, must put forth effort to persuade other management personnel in the company in order to make progress on the project. The best method to approve the feasibility of a project without a high investment would be creating a future stage visualization containing all the objects pertaining to "what, where, who, why and how". One simple video can be a unique and powerful presentation tool with respect to manufacturing communication. It allows questions, problems, challenges, opportunities, and progress to be visible and eliminates unnecessary misunderstanding and non-effective communication. Five key points are summarized below based on the lessons learned from the case study.

(1) Being fully aware of the purpose of the video is the key to set up the proper level of detail in the visualization.

(2) It is rare that everyone can agree on a single plan, be prepared to provide multi-scenario visualizations for optimal visualization support.

(3) Make sure the consistency of the visualization s. Because the objects created in the 3D modelling maybe not flow through the process which gives opportunities for mistake where the same object in one scene looks different in the other scene.

(4) Effective communication between the visualization team and operation side, as well as the time frame, is integral to delivering a successful visualization.

(5) Be prepared for editing and re-editing as part of the process of future stage visualization; new problems will be revealed and fixed through $3 \mathrm{D}$ visualization rather than re-building the production line to address each problem in real time.

\section{CASE STUDY}

3D/4D visualization modelling for current state and future state were created for a case study of prototype modular housing to facilitate communication with the on-site workers and higher management level personnel. The visualization illustrated in Figure 1 represents the animated stages for joist floor panel manufacturing. Based on visualization of the factory's current practice, various kinds of waste were simulated and tracked. An improvement methodology was created by 
the factory team to highlight the implementation of various improvements. The continual discussions and brain storming sessions involving various project parties based on the proposed visualization boosted the productivity and generated an applicable improvement strategy.

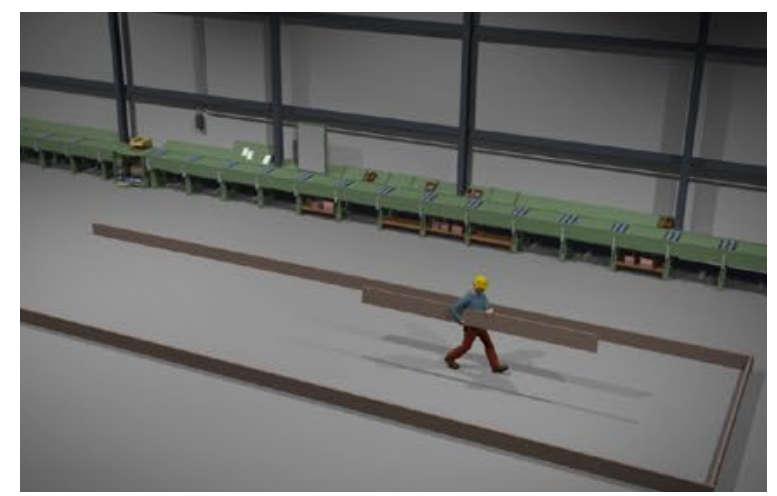

Stage 1: Joists manually delivered

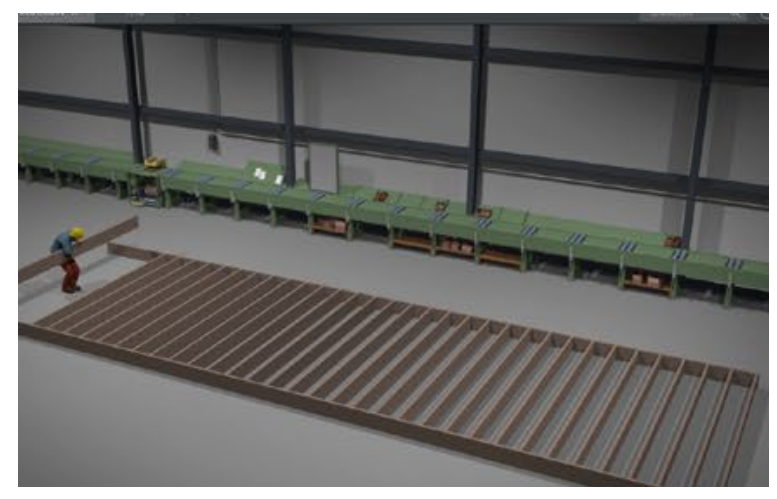

Stage 3: Joists floor panel

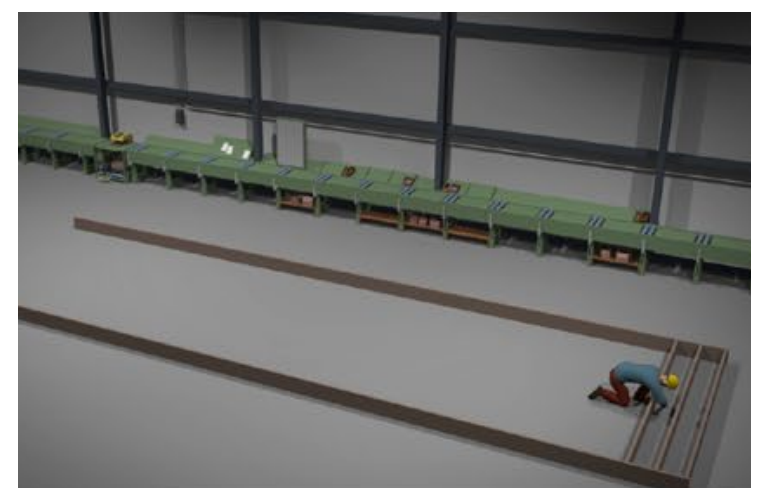

Stage 2: Joists manually set down

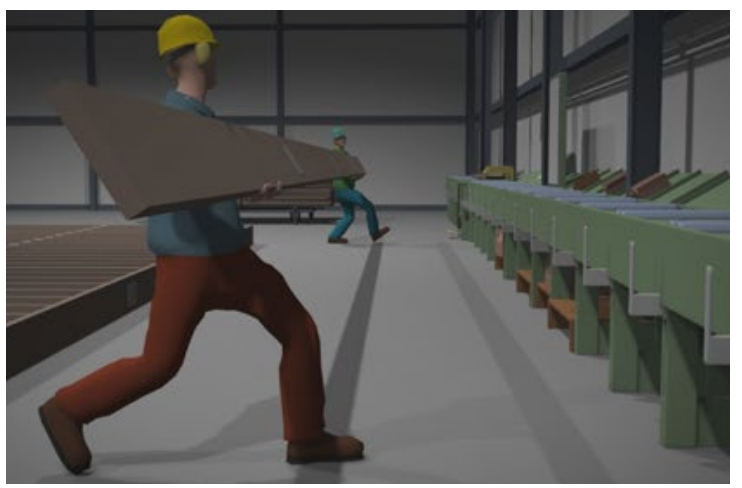

Stage 4: Repeated physical work

Figure 1: Current Stage: snapshots from the video clip.

Based on the visualization analysis and the factory team suggestions, the proposed improvement is presented as follows:

(1) Relocating construction activities to achieve balanced stations; and

(2) Post the cycle time of each station based on the proposed visual representation and suggested quality improvement from the floor.

Some value added activities were moved upstream to allow for balanced cycle time, such as selected floor and wall wiring activities (see Figure 2); and selected insulations activities (see Figure 3). Value added activities includes but not limited to electrical cord wiring, joint assembly, and insulation installation. 


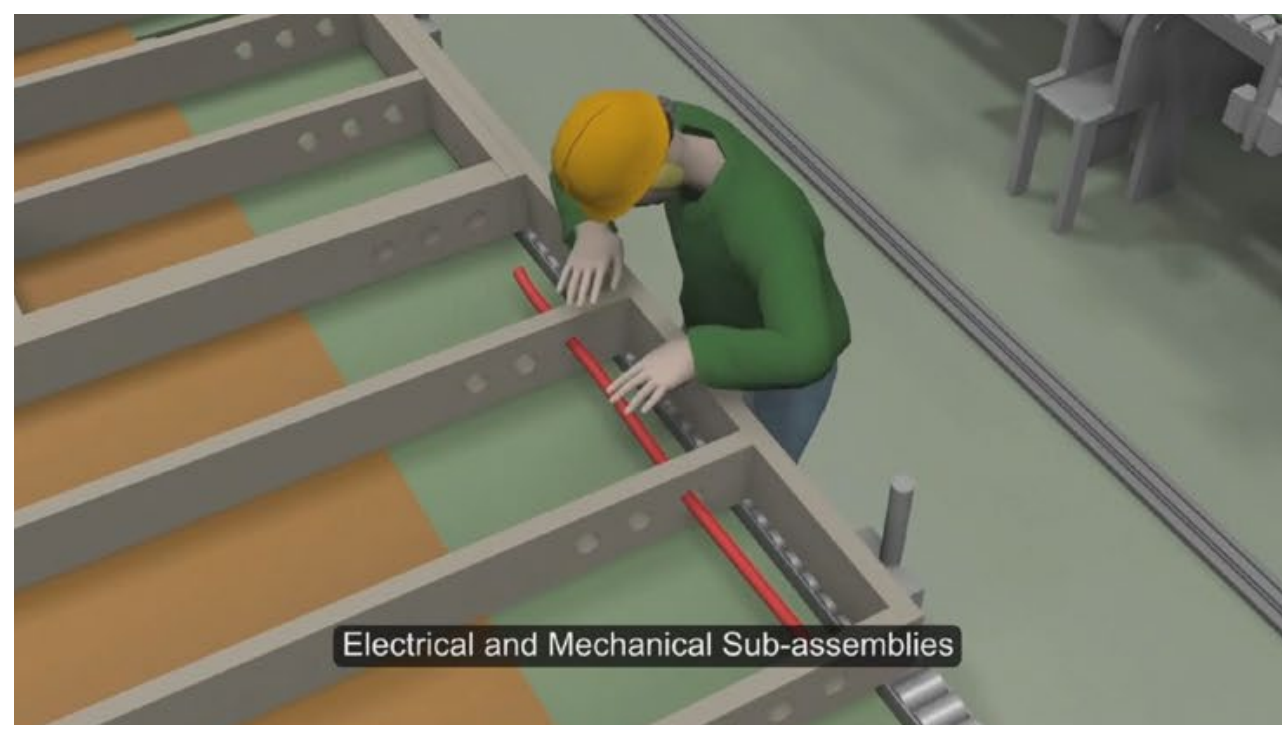

Figure 2: Proposed improvements: value added activities moved to different stations

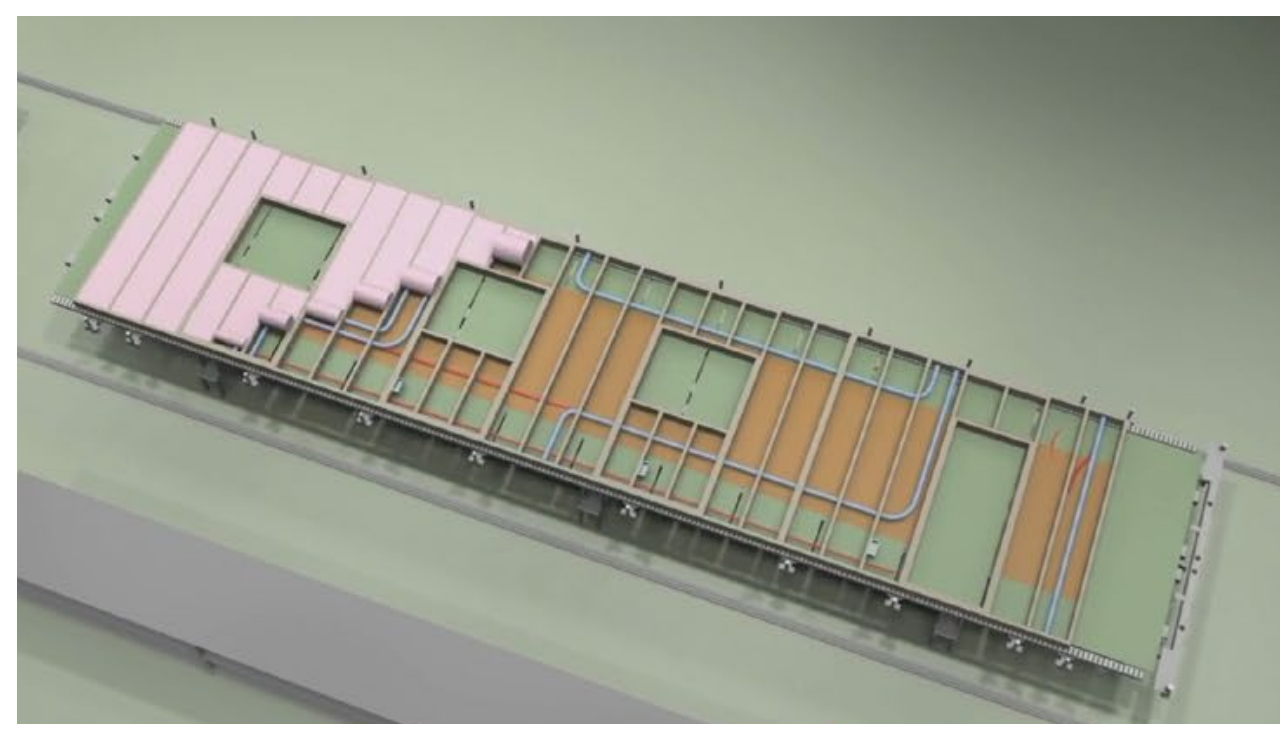

Figure 3: Moving insulation activity upstream

\section{CONCLUSION}

A range of activities in modular construction production can be better performed with the provision of a visualization tool. Typical modular activities that can be performed with the provision of a visualization tool are assembly process, wood framing, and cords insulation. The factory team might decide to perform a visualization to a specific sectors in the production line, as visualization is a tool to help discussion making and improve overall productivity. Because of the application of visualization in construction projects, certain benefits arise from the resultant communication improvement between parties involved. These benefits include two aspects of communication among project parties and production improvement. The benefits from 3D/4D visualization tool are recognized from the proposed case study applications through facilitating communication 
among the project team and propose solutions for production improvement. Various kinds of waste were eliminated throughout the production line. All non-value added activities were eliminated and rescheduled to improve the productivity of the proposed modular housing construction.

\section{REFERENCES}

"Speakers Give Sound Advice.". (1911, March 28). Syracuse Post Standard, 18. Syracuse, New York, United States: Advance Publications.

Bazjanac, V. (2002). Early lessons from deployment of IFC compatible software. Proc. fourth Euro. conf. product process modelling (pp. 9-16). Portoroz: SLO.

Bouchlaghem, D., Shang, H., Whyte, J., \& Ganah, A. (2005). Visualisation in architecture, engineering and construction (AEC). Automation in Construction, 14, 287-295.

Burkhard, R. A. (2004). Learning from Architects: The Difference between Knowledge Visualization and Information Visualization. Proceedigns of the Eighth International Conference on Information Visualization.

Hartmann, T., Gao, J., \& Fischer, M. (2008). Areas of Application for 3D and 4D Models on Construction Projects. Journal of Construction Engineering and Management, 776-785.

Howard, H. C., Levitt, R. E., Paulson, B. C., Pohl, J. G., \& Tatum, C. B. (1989, January). Computer Integration: Reducing Fragmentation in AEC Industry. Journal of Computing in Civil Engineering.

Kamat, V. R., \& Martinez, J. C. (2000). 3D Visualization of Simulated Construction Operations. Simulation Conference, 2000, (pp. 1933-1937).

Kang, J. H., \& Lho, B.-C. (2003). Impact of 4D Visualization on the Cognitive Process of Detecting the Logical Errors in the Construction Schedule. Proceedings of the 2003 American Society for Engineering Education Annual Conference \& Exposition.

Khanzode, A., Fischer, M., \& Reed, D. (June, 2008). Benefits and Lessons Learned of Implementing Building Virtual Design and Construction (VDC) Technologies for Coordination of Mechanical, Elecrical, and Plumbing (MEP) Systems on a Large Healthcare Project. ITcon, (pp. 324-342).

Messner, J. I., \& Horman, M. J. (September, 2003). Using Advanced Visualization Tools to Improve Construction Education. CONVR 2003. Virginia Tech.

Russell, A. D., Chiu, C.-Y., \& Korde, T. (2009). Visual representation of construction management data. Automation in Construction, 1045-1062.

Staub-French, S., \& Khanzode, A. (2007). 3D and 4D Modeling for Design and Construction Coordination: Issues and Lessons Learned. ITcon, (pp. 381-407).

Titelman, G. (1996). Random House Dictionary of America's Popular Proverbs and Sayings. Random House Reference. 